Ethiopian Journal of Environmental Studies \& Management 8(Suppl. 2): 881 - 892, 2015.

ISSN:1998-0507

doi: http://dx.doi.org/10.4314/ejesm.v8i2.3S

Submitted: May 06, 2015

Accepted: November 02, 2015

\title{
CHITOSAN GRAFTED MODIFIED MAIZE COB FOR REMOVAL OF LEAD AND CHROMIUM FROM WASTEWATER
}

\author{
${ }^{*}$ OKOYA, A.A., ${ }^{1}$ AKINYELE, A.B., ${ }^{1}$ AMUDA, 0.S. ${ }^{2}$ AND OFOEZIE, I.E. ${ }^{1}$ \\ ${ }^{1}$ Institute of Ecology and Environmental Studies, Obafemi Awolowo University, Ile - Ife, \\ Nigeria \\ ${ }^{2}$ Ladoke Akintola University of Technology, Ogbomoso, Nigeria
}

\begin{abstract}
Agro wastes are vast abundant raw material whose potential is still under-utilized. Availability and biodegradability are a few features of these materials for utilization. The present study was aimed at exploiting the option of utilizing maize cob for remediation of industrial effluent. Maize cob was collected, pulverized and sieved into $150-300 \mu \mathrm{m}$ particle size. The carbonized materials obtained were then characterized using Energy Dispersive Xray (EDX) and Scanning Electron Microscope (SEM) for elemental and surface morphology determination. Standard solutions of $\mathrm{Cr}$ and $\mathrm{Pb}$ ion solution were prepared. The cob were used to treat effluent under the following conditions: agitation time (30 - $150 \mathrm{~min})$, adsorbent dosage $(0.5-2.5 \mathrm{~g})$, metal ion concentration $(5-25 \mathrm{ppm})$ and particle size effect. From the result, $90 \%$ and $38 \%$ removal efficiency were obtained for $\mathrm{Pb}$ and $\mathrm{Cr}$ ions solution respectively. The potential of maize cob was established for the treatment of lead polluted wastewater.
\end{abstract}

Key Words: Maize cob; Heavy metals; wastewater; Adsorption isotherms

\section{Introduction}

There has been immense impact of man on the environment ever since the scientific and industrial revolution and has failed to realize that these impacts affect the balance of the ecosystem as a whole. Enormous industrial installations and population explosion in cities are the main outcome of the modern civilization (Subramani and Sindhu, 2012). "Population is a consequence of the entire phenomena of civilization" (WHO, 1972). The pollution problem in its present form is therefore as a result of the contemporary population explosion, aggravated by parallel explosion of economic, technical and scientific forces. Rapid increase in industrialization has led to increase disposal of heavy metals into the environment.

Heavy metals are metals with density above the density of earth $\left(5.2 \mathrm{~g} / \mathrm{cm}^{3}\right)$. They are a group of elements between Copper and Bismuth on the periodic table of elements. The pollution and toxic effect of these metals has received wide spread attention in the recent years. The most often toxic heavy metals are nickel, chromium, lead, mercury, arsenic, zinc, copper, manganese, iron and cadmium (Nriagu, 1996). These heavy metals are not degradable into non-toxic product, their concentration in the environment especially in the wastewater before discharge therefore needs to be reduced to acceptable level. Removal of these metals 
Chitosan Grafted Modified Maize Cob For Removal of Lead and Chromium.................KOYA et al.

from the environment through conventional methods such as coagulation, ion exchange, membrane separation and precipitation has been established (Nesernejad et al., 2004; Kartal et al., 2008). These methods are limited in their application even though some of them are effective. Precipitation processes generates sludge that needs further treatment. Electrolytic and membrane processes are costly and require high energy consumption and moreover the secondary wastes generated sometimes are difficult to treat. Although the sorption processes using ion exchange resins and activated carbon as sorbents are efficient, they are limited in their application due to the high cost of these most used sorbents (Oliveira et al., 2010). The use of agricultural waste materials, especially those containing cellulose has shown potential biosorption capacity instead of constituting nuisance to the environment (Sud et al., 2008).

This study examined the adsorption and treatment of heavy metal from aqueous solutions using maize cob char. The main focus of the study was to investigate the efficiency of maize cob char (modified and unmodified) for the removal of chromium (VI) and lead (II); and comparing it with commercial activated carbon.

\section{Materials and Methods}

\section{Preparation of Maize Cob Char}

The maize cobs used for this research were collected from Obafemi Awolowo University Teaching and Research Farm. The sample was dried ground and sieved to $150-300 \mu \mathrm{m}$ particle size. The char of the maize cob was carried as previously described with modification (Amuda and Ibrahim, 2006). Pulverized sample (15 g) was placed in a furnace at $500{ }^{\circ} \mathrm{C}$ for $2 \mathrm{~h}$ and later soaked in liquid nitrogen for $1 \mathrm{~h}$. The carbonaceous substance was then washed with distilled water to remove any adherent powder.

\section{Activation of Maize Cob Char}

The carbonaceous samples was treated with $2 \% \mathrm{H}_{2} \mathrm{SO}_{4}(\mathrm{v} / \mathrm{v})$ in an incubator at a temperature of $110{ }^{\circ} \mathrm{C}$ for $24 \mathrm{~h}$. The treated carbonaceous sample was then soaked in distilled water until the $\mathrm{pH}$ was stabilized. Then, the sample was soaked in $2 \%$ $\mathrm{NaHCO}_{3}$ till residual acid was removed. The acid-treated maize cob carbon was then dried overnight in an oven (Met-tler, England) at $110{ }^{\circ} \mathrm{C}$, cooled and stored in desiccators until use (Kadirvelu et al., 2001).

\section{Chitosan Preparation}

The less than $2 \mathrm{~mm}$ size powdered snail shell $(50 \mathrm{~g})$ was deproteinized by weighing into a $500 \mathrm{ml}$ beaker and $200 \mathrm{ml}$ of $4 \%(\mathrm{w} / \mathrm{v}) \mathrm{KOH}$ was added with constant stirring for $6 \mathrm{~h}$ at $80{ }^{\circ} \mathrm{C}$. The residue was washed with distilled water after filteration until it is free of base and then dried at $100{ }^{\circ} \mathrm{C}$ for $2 \mathrm{~h}$. The deproteinized snail shell residue was poured into a $250 \mathrm{ml}$ conical flask and 100 $\mathrm{ml}$ of $3 \%(\mathrm{v} / \mathrm{v}) 1 \mathrm{M} \mathrm{HCl}$ was added and placed on a magnetic stirrer for $3 \mathrm{~h}$ at 30 ${ }^{\circ} \mathrm{C}$. This process is called demineralization. The content was later filtered and the residue was washed until it is free of acid. Litmus paper was used to test if the residue is acid free. The acid free residue was then dried at $90{ }^{\circ} \mathrm{C}$ for $1 \mathrm{~h}$ after which it was decolourized by refluxing in acetone for 3 $\mathrm{h}$ at $60{ }^{\circ} \mathrm{C}$. The content was filtered and dried. A snow white residue called chitin was obtained. The chitin was poured into a $250 \mathrm{ml}$ conical flask for deacetylation, 50 $\%$ (w/v) $\mathrm{NaOH}$ solution was added and stirred at $30{ }^{\circ} \mathrm{C}$ for $4 \mathrm{hrs}$. After filteration, the residue, which is Chitosan (2acetamido-2-deoxy- $\beta$-D-glucose-N(acetylglucosamine)), was then washed and dried at $90{ }^{\circ} \mathrm{C}$ for $1 \mathrm{hr}$ (Abdou et al., 2008; Zhen et al., 2013; Okoya et al., 2014). 


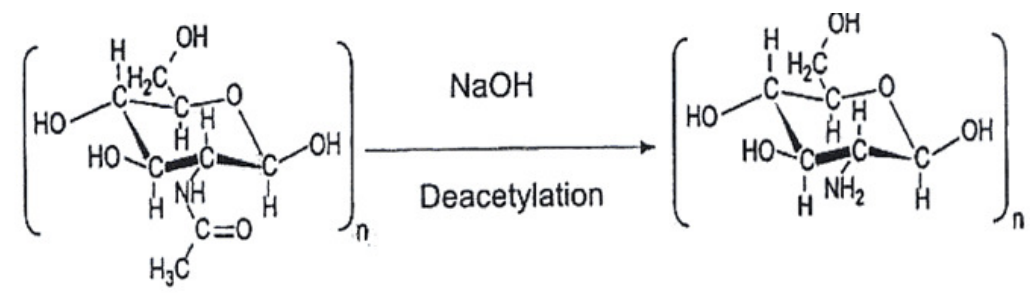

Chitin
2-acetamido-2-deoxy- $\beta$-D-glucose-( $\mathrm{N}$-acetylglucan)

Chitosan

2-acetamido-2-deoxy- $\beta$-D-glucose-( $\mathrm{N}$-acetylglucosamine)

Source: (Amuda et al., 2007)

\section{Chitosan Gel Preparation}

About $5 \mathrm{~g}$ of chitosan was slowly added to $100 \mathrm{ml}$ of $10 \%(\mathrm{w} / \mathrm{v})$ oxalic acid with constant stirring. The mixture was also heated to $40-50{ }^{\circ} \mathrm{C}$ to facilitate mixing. A whitish viscous gel of chitosanoxalic acid mixture was formed (Amuda et al., 2007 and 2009).

\section{Adsorbent Modification}

The chitosan gel $(100 \mathrm{ml})$ was diluted with water $(\sim 500 \mathrm{ml})$ and heated to $40-50$ ${ }^{\circ} \mathrm{C}$. $50 \mathrm{~g}$ of maize cob char was slowly added to the diluted gel in separate container, and mechanically agitated using a shaker at $200 \mathrm{osc} / \mathrm{min}$ for $24 \mathrm{~h}$. The gel coated adsorbent were then washed with distilled water and dried. The chitosan coated maize cob char was then soaked in $0.5 \%$ (w/v) $\mathrm{NaOH}$ solution for $3 \mathrm{~h}$. It was then extensively rinsed with distilled water and dried in an oven at $102{ }^{\circ} \mathrm{C}$ for $2 \mathrm{~h}$, cooled at room temperature and stored in desiccator.

\section{Batch Biosorption Studies}

Experiments were conducted in 250 $\mathrm{mL}$ Erlenmeyer flasks containing known $100 \mathrm{ml} \mathrm{Cr}$ (VI) synthetic solutions and 1.5 $\mathrm{g}$ of the adsorbent. Flasks were agitated on a shaker at $400 \mathrm{osc} / \mathrm{m}$ constant shaking. The following parameters were investigated; Biosorbent dose (0.5, 1.0, 1.5, 2.0 and $2.5 \mathrm{~g})$, Contact time $(30,60$, 90, 120 and $150 \mathrm{~min}$ ) and Metal ion concentration $(5,10,15,20$ and $25 \mathrm{mg} / \mathrm{L})$. The mixture was filtered using Whatman no.1. and the filtrate was analysed spectrophotometrically using atomic absorption spectroscopy (AAS).

The removal efficiency (E) of adsorbent on $\mathrm{Cr}$ (IV) are measured as follows:

$E(\%)=\frac{C_{\mathrm{i}}-C_{\mathrm{f}}}{C_{\mathrm{i}}} \times 100$,

where $\mathrm{C}_{\mathrm{i}}$ and $\mathrm{C}_{\mathrm{f}}$ are the initial and final concentration of $\mathrm{Cr}$ (VI) (mg/L) in wastewater, respectively. The same procedure was repeated for the adsorption of $\mathrm{Pb}$ (II).

\section{Data Evaluation}

The amount of metal adsorbed by the adsorbent was calculated using a mass balance equation which has been previously used in evaluating the amount of metal ion uptake by maize cob char. The equation is given as

$\mathrm{Q}=\mathrm{v}\left(\mathrm{C}_{\mathrm{i}}-\mathrm{C}_{\mathrm{f}}\right) / \mathrm{m}$

where Q is the metal uptake (mg metal per $\mathrm{g}$ biosorbent), $\mathrm{v}$ is the liquid sample volume $(\mathrm{ml}), \mathrm{C}_{\mathrm{i}}$ is the initial concentration of the metal in the solution $(\mathrm{mg} / \mathrm{L}), \mathrm{C}_{\mathrm{f}}$ is the final (equilibrium) concentration of the metal in the filtrate $(\mathrm{mg} / \mathrm{L})$ and $\mathrm{m}$ is the amount of the added biosorbent on the dry basis $(\mathrm{g})$.

\section{Results and Discussion}

\section{Characterisation of the Maize cob char}

The maize cob char elemental composition was analysed using Energy Dispersive X-ray Micro Analyzer (EDX) 
while the morphology was determined using Scanning Electron Microscope (SEM). As shown in figure 1, the spectra showed the elemental presence of $\mathrm{C}, \mathrm{K}$, $\mathrm{Ca}, \mathrm{Mg}, \mathrm{Al}, \mathrm{Si}, \mathrm{P}$ and $\mathrm{Cl}$ which has been said to support ion exchange, chelation, coordination and complexation (Alayande et al., 2011; Michaud, 2011). Figure 2 revealed the agglomeration of the maize cob char particles which has been said to aid adsorption of metals (Edwin, 2008; Grabriela et al., 2006).

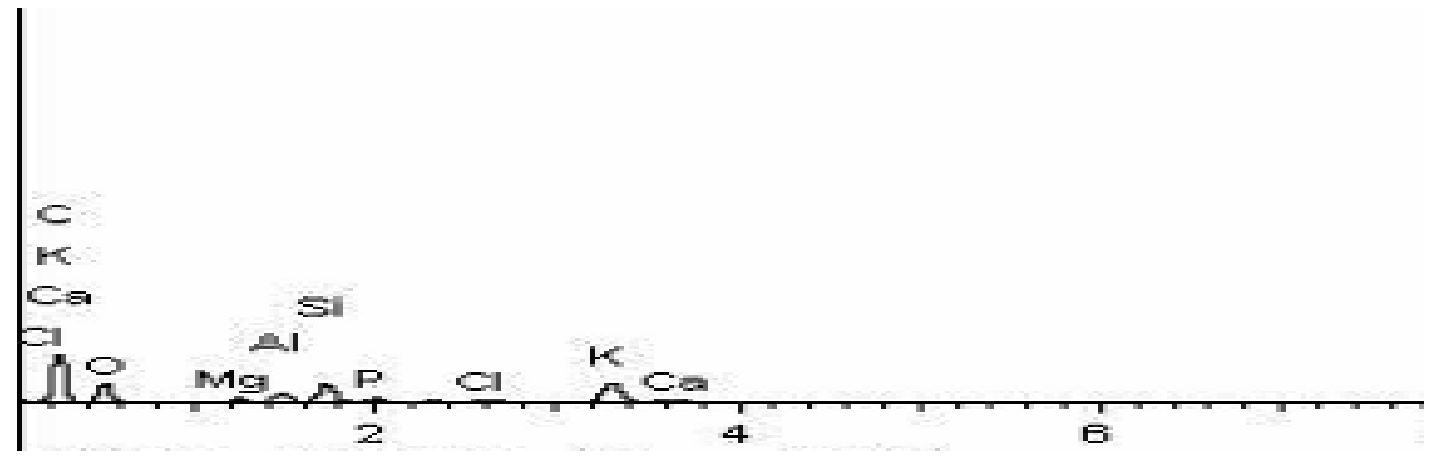

Figure 1: EDX spectra of maize cob char

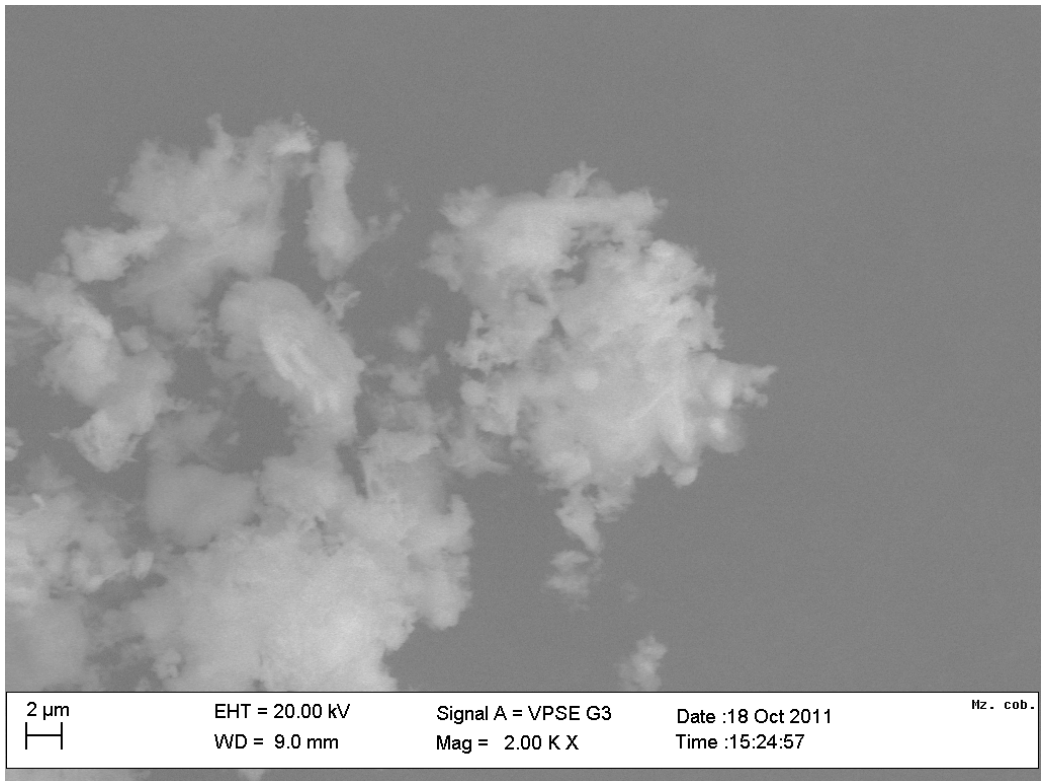

Figure 2: Maize cob char SEM image

\section{Effect of Initial Metal Ion Concentration}

Figures 3 and 4 show the effect of initial metal ion concentration on the adsorption of $\mathrm{Cr}$ (VI) using commercial activated carbon, modified maize cob char and unmodified maize cob char. From the figures, it is observed that as the metal ion concentration increases the removal efficiency of commercial activated carbon, modified maize cob char and unmodified maize cob char increased for $\mathrm{Pb}^{2+}$ while for $\mathrm{Cr}^{6+}$, the removal efficiency of activated carbon increase as metal ion concentration increases but decrease for unmodified maize cob char as metal ion concentration increases. Modified maize cob char showed fluctuation in the removal efficiency of $\mathrm{Pb}$. These may be due to the 
number of vacant site that is yet to be occupied and metal ion are competing for these available sites (Olu-owolabi et al., 2012). The decrease in removal efficiency exhibited by the adsorption of $\mathrm{Cr}^{6+}$ is due to the rapid binding of the available active site that occur at the early initial $\mathrm{Cr}^{6+}$ concentration which now create a limited active site that attained saturation at

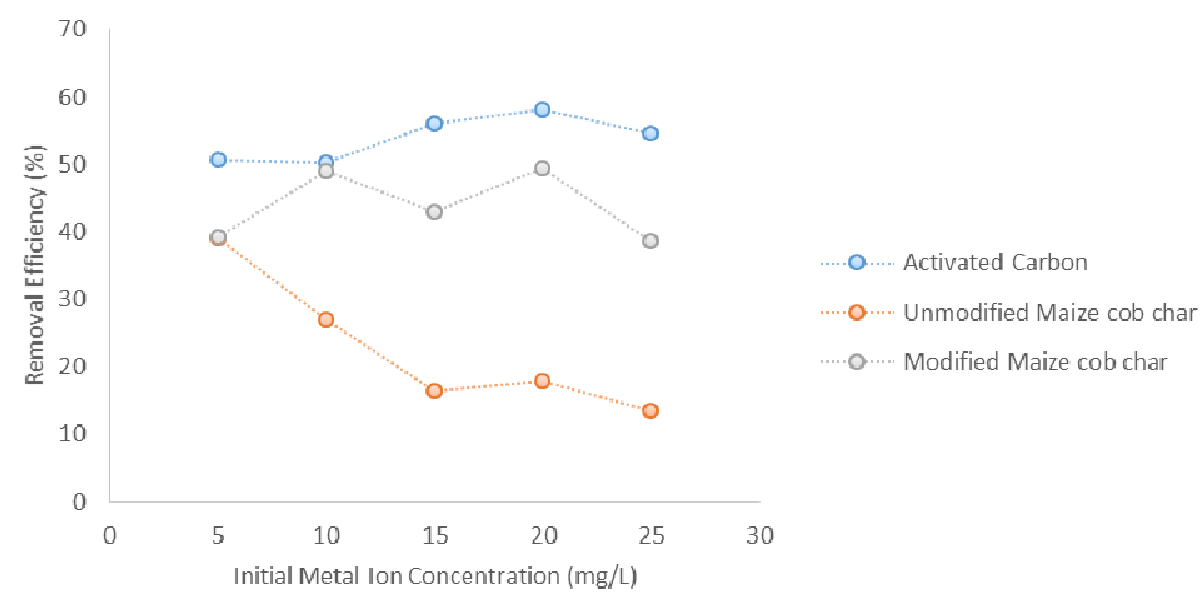

Figure 3: Effect of initial ion concentration on removal efficiency of $\mathrm{Cr}$ (VI) by the adsorbents. Agitation time: $45 \mathrm{~min}$; agitation speed: $400 \mathrm{osc} / \mathrm{min}$; dose of each adsorbent: $1.5 \mathrm{~g}$.

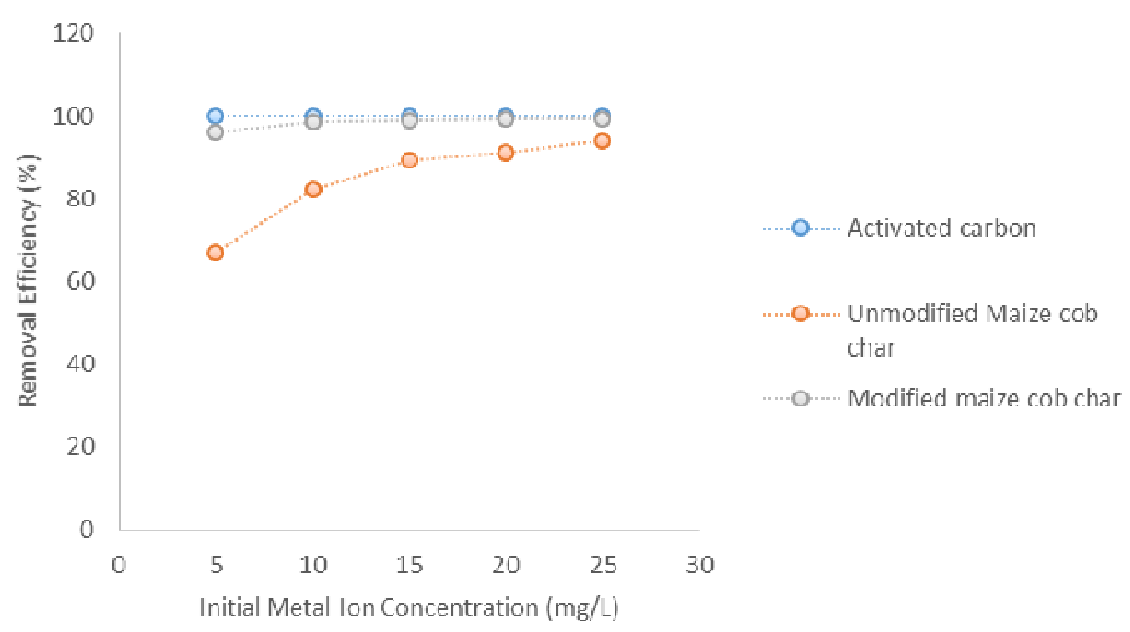

Figure 4: Effect of initial ion concentration on removal efficiency of $\mathrm{Pb}$ (II) by the adsorbents. Agitation time: $45 \mathrm{~min}$; agitation speed: $400 \mathrm{osc} / \mathrm{min}$; dose of each adsorbent: $1.5 \mathrm{~g}$.

\section{Effect of Adsorbent Dosage}

Figures 5 and 6 exhibit the influence of adsorbent dosage on the sorption of $\mathrm{Cr}^{6+}$ increased concentration (AjayKumar et al., 2009).

The adsorption of the two metals $\left(\mathrm{Cr}^{6+}\right.$ and $\mathrm{Pb}^{2+}$ ) using commercial activated carbon showed higher removal efficiency than maize cob char for the metals but the removal efficiency of $\mathrm{Pb}$ (II) by maize cob char is greater than that of $\mathrm{Cr}^{6+}$ by the same adsorbent. 
reduce from $20.9 \%$ to $18 \%$ as dosage increase from $1.5 \mathrm{~g}$ to $2.0 \mathrm{~g}$ and pick up later to $23.33 \%$ as dosage increased to 2.5 g. In the case of $\mathrm{Pb}^{2+}$, the removal efficiency exhibited by unmodified maize cob char increase from $97.75 \%$ to $99.4 \%$ as adsorbent dosage increases from $0.5 \mathrm{~g}$ to $2.5 \mathrm{~g}$. Meanwhile, activated carbon and modified maize cob char showed a decrease in removal efficiency of $\mathrm{Cr}^{6+}$ as adsorbent dosage increases but activated carbon showed a slight increase in removal efficiency of $\mathrm{Pb}^{2+}$ as the dosage increases while modified maize cob char showed initial increase in removal efficiency as the adsorbent dose increase to $1.5 \mathrm{~g}$ then decreases. The increase removal efficiency trend shown by the adsorbent is because the number of adsorbent particles increases as the adsorbent dose increases and that makes the greater availability of exchangeable sites for adsorption (Ijagbemi and Dong-Su, 2009; Mahmoud et al., 2012). The decrease in removal efficiency in other case is as a partial overlapping or aggregation of adsorbent surface area available to ion, which occurs at high biomass concentration given rise to a decrease of active sites (Gönen and Serin, 2012).

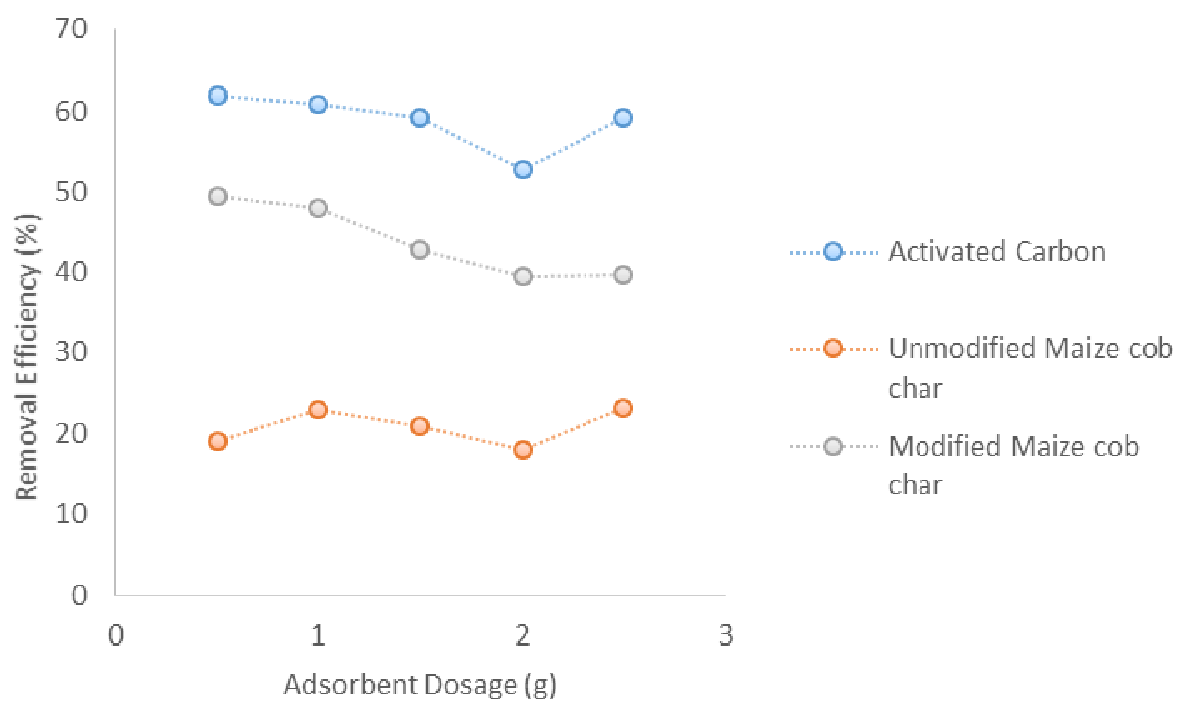

Figure 5: Effect of dose of the adsorbents on the removal efficiency of $\mathrm{Cr}$ (VI). Cr (VI) Concentration: $30 \mathrm{mg} / \mathrm{L}$; Agitation time: $60 \mathrm{~min}$; Agitation speed $400 \mathrm{osc} / \mathrm{min}$ 


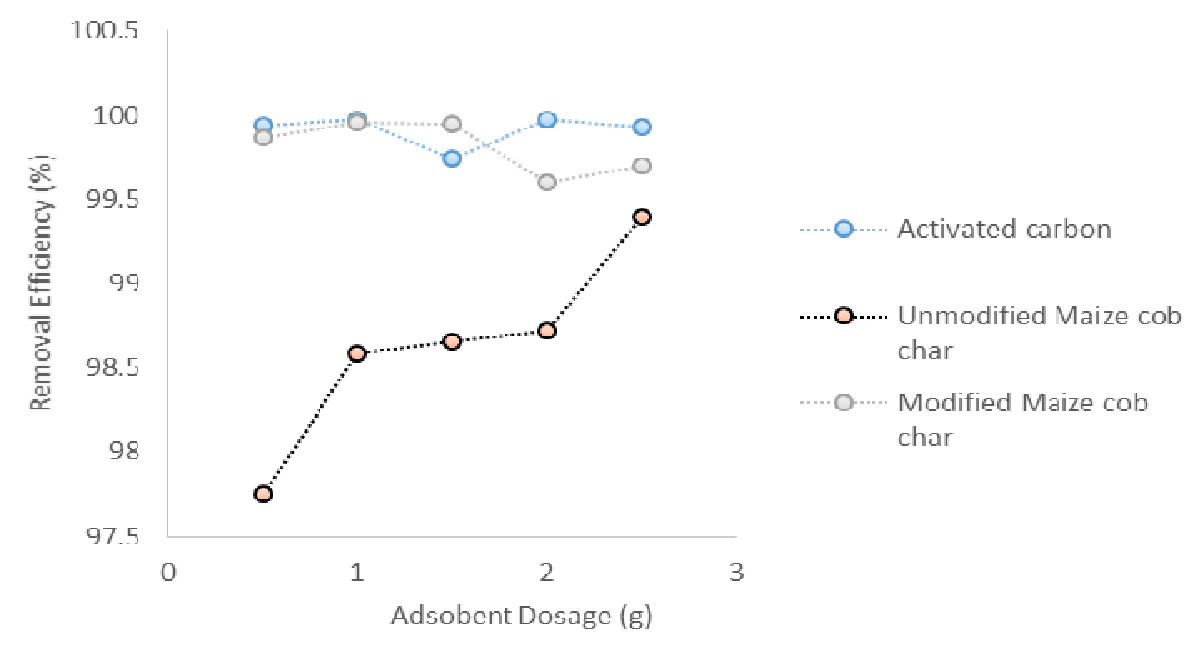

Figure 6: Effect of dose of the adsorbents on the removal efficiency of $\mathrm{Pb}$ (II). $\mathrm{Pb}$ (II) Concentration: $30 \mathrm{mg} / \mathrm{L}$; Agitation time: $60 \mathrm{~min}$; Agitation speed $400 \mathrm{osc} / \mathrm{min}$

\section{Effect of Agitation time}

As seen in Figure 7, the removal efficiency of $\mathrm{Cr}^{6+}$ by unmodified maize cob char increases from 30 to $60 \mathrm{~min}$ which later drop as agitation time increases from 30 to $150 \mathrm{~min}$, meanwhile that of commercial activated carbon and modified maize cob char increase as agitation time increases. In Fig. 8, the removal efficiency of $\mathrm{Pb}^{2+}$ using unmodified maize cob char initially increased and then gradually remained constant with increase in agitation time and reached the equilibrium at 120 min but equilibrium was reached at early stage (i.e. $30 \mathrm{~min}$ ) when using commercial activated carbon and modified maize cob char. These result showed that

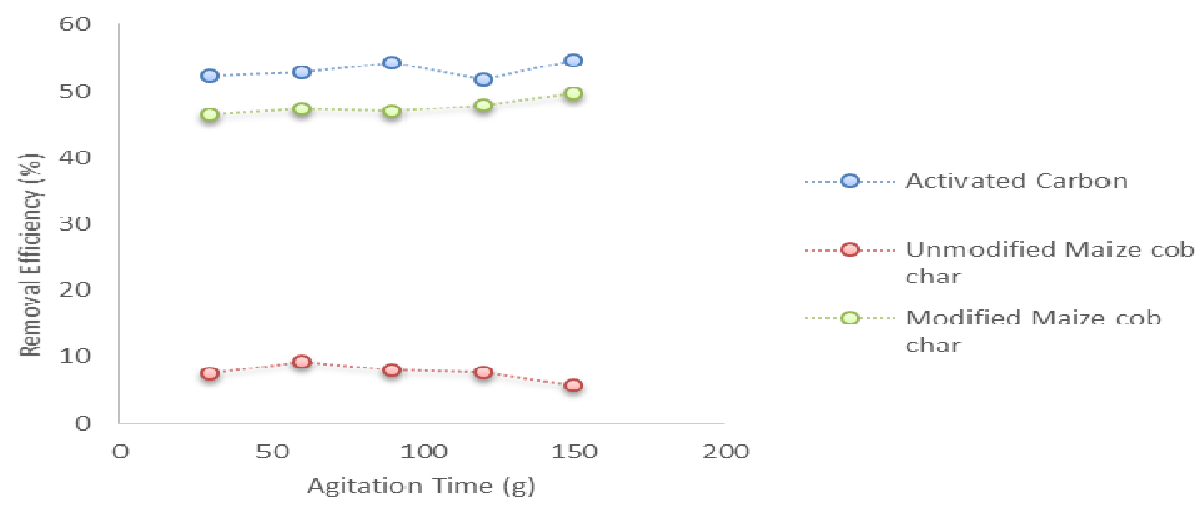

initially the number of vacant sites was large which later tailed off as the vacant active site is been saturated (Sugashini and Gopalakrishnan, 2012). Also, the fast adsorption at the initial stage observed with commercial activated carbon and modified maize cob char was probably due to the initial concentration gradient between the adsorbate in solution and the number of vacant sites available on the adsorbent surface at the beginning while the decrease in efficiency may be due to limited mass transfer of the adsorbate molecules from the bulk liquid to the external surface of the adsorbents (Onundi et al., 2011).

Figure 7: Effect of agitation time on removal efficiency of $\mathrm{Cr}$ (VI) by the adsorbents. Cr (VI) Concentration: $20 \mathrm{mg} / \mathrm{L}$; agitation speed: $400 \mathrm{osc} / \mathrm{mim}$; dose of each adsorbent: $1.0 \mathrm{~g}$ 


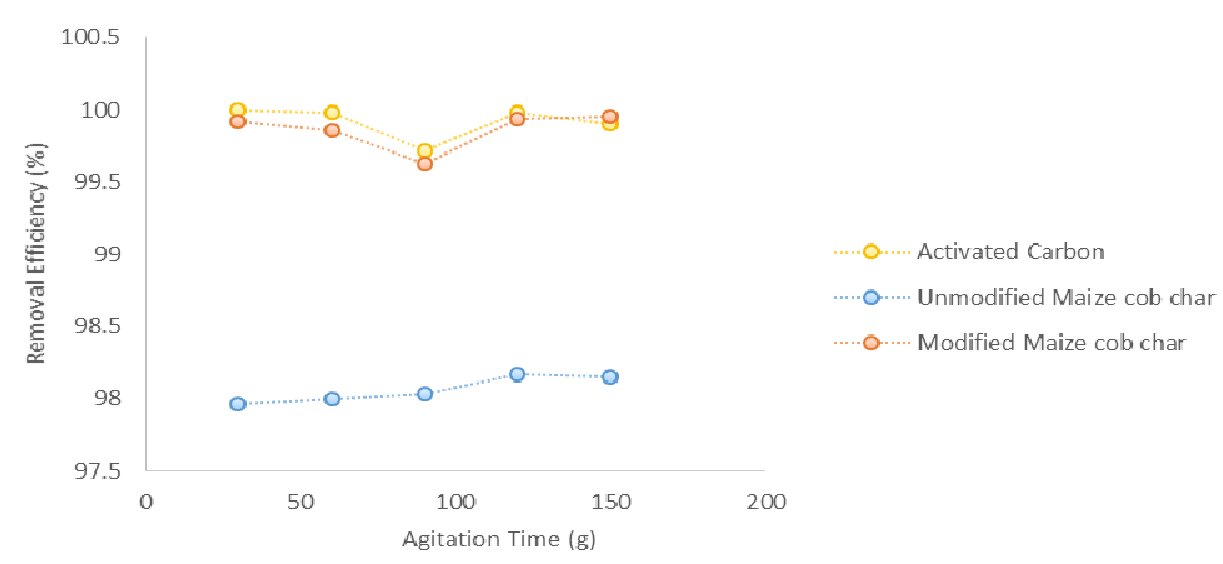

Figure 8: Effect of agitation time on removal efficiency of $\mathrm{Pb}$ (II) by the adsorbents. $\mathrm{Pb}$ (II) Concentration: $20 \mathrm{mg} / \mathrm{L}$; agitation speed: $400 \mathrm{osc} / \mathrm{min}$; dose of each adsorbent: $1.0 \mathrm{~g}$

\section{Effect of particle size}

The effect of particle size on the removal efficiency of $\mathrm{Cr}$ and $\mathrm{Pb}$ was study in Fig. 9. The particle sizes used were 150, 212 and $300 \mu \mathrm{m}$, respectively. Other parameters such as adsorbent dose, initial ion concentration and agitation time were kept constant; temperature and agitation speed were kept at $25{ }^{\circ} \mathrm{C}$ and $400 \mathrm{osc} / \mathrm{min}$, respectively. The removal efficiency $\mathrm{Cr}$ decrease as particle size increases. This may be as a result of the fact that smaller particles give large surface areas. In the case of $\mathrm{Pb}$, removal efficiency increase as particle size decreases but $212 \mu \mathrm{m}$ particle size show highest removal efficiency which may be that the particles are spherical in shape. Larger particles with spherical shape, in general, present higher external mass transfer than small particle size (Leusch and Volesky, 1995).

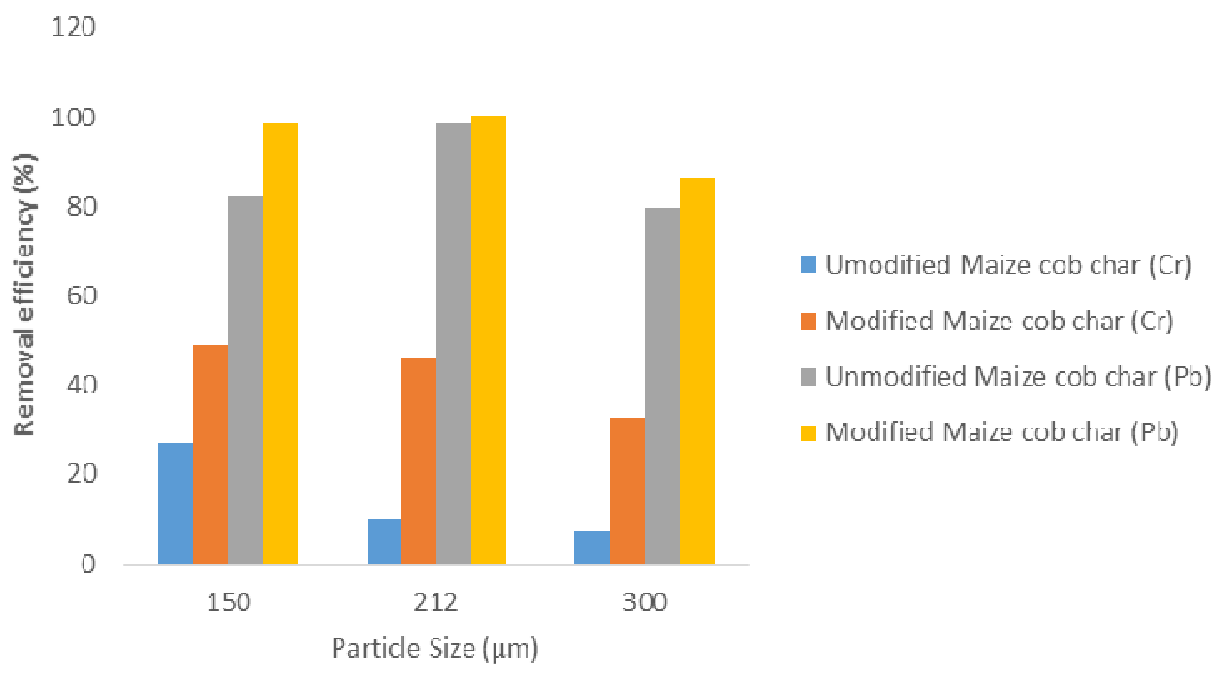

Figure 9: Effect of the adsorbent particle size on the removal efficiency of $\mathrm{Cr}^{6+}$ using maize cob char. Metal concentration: 10mg/L; Agitation time: $45 \mathrm{~min}$; agitation speed: $400 \mathrm{osc} / \mathrm{min}$; adsorbent dosage: $1.5 \mathrm{~g}$ 


\section{Adsorption Isotherm}

Langmuir and Freundlich models are the most commonly used theoretical model to generate adsorption isotherm. Langmuir model assumption state that uptake of metal ions occurs on a homogenous surface by monolayer adsorption without any interaction between adsorbed ions while the assumption of Freundlich model is based on adsorption on heterogenous surface.

The experimental data were analyzed according to the linear form of the Langmuir (Kocaoba et al., 2007) and Freundlich (Sprynskyy et al., 2006) model. The linearized equation of Langmuir model is commonly represented by:

$1 / \mathrm{Q}=1 / \mathrm{Q}_{\max }\left(1 / \mathrm{b} \mathrm{C}_{\mathrm{f}}+1\right)$

Where $\mathrm{Q}_{\max }$ is the maximum metal uptake under the given conditions, $\mathrm{b}$ a constant related to the affinity between the adsorbent and sorbate.

The linearized equation of Freundlich model is commonly represented by:

$\log Q=\log k+1 / n \log C_{f}$

Where $\mathrm{k}$ and $\mathrm{n}$ are Freundlich constant, which correlated to the maximum adsorption capacity and adsorption intensity, respectively.

Table 1 show the applicability of Langmuir and Freundlich model to the metals using modified and unmodified maize cob char adsorbent. The two models fitted well for the adsorption studies of $\mathrm{Cr}$ rather than for the adsorption of $\mathrm{Pb}$. This is because of the higher correlation coefficient depicted by the two models (Table 1). $\mathrm{Q}_{\max }$ value which is the adsorption capacity determined from the slope of Langmuir indicate a good adsorbing capacities of the adsorbent for $\mathrm{Pb}$ than $\mathrm{Cr}$. The $1 / \mathrm{n}$ values less than 1 indicate favourable adsorption (Al-Sultani and Al-Seroury, 2012). Going by the value of $1 / \mathrm{n}$ for the sorption of $\mathrm{Pb}$ (II) ion by the modified and unmodified maize cob char adsorbents in Table 1 which are higher than that of the sorption of $\mathrm{Cr}$ (VI) ion by the adsorbents, it indicate favourable adsorption for $\mathrm{Pb}$ than $\mathrm{Cr}$. A smaller value of $1 / \mathrm{n}$ indicates better adsorption mechanism and formation of relatively stronger bond between adsorbate and adsorbent (Kose et al., 2012; Alfa et al., 2012).

Table 1: Langmuir and Freundlich constants for the adsorption of $\mathrm{Cr}^{6+}$ and $\mathrm{Pb}^{2+}$ at $25^{\circ} \mathrm{C}$ using modified and unmodified coconut shell char

\begin{tabular}{lllllll}
\hline & \multicolumn{4}{l}{ Langmuir constants } & \multicolumn{3}{l}{ Freundlich constants } \\
\cline { 2 - 7 } & $\mathrm{b}(\mathrm{L} / \mathrm{mg})$ & $\mathrm{Q}_{\max }(\mathrm{mg} / \mathrm{g})$ & $\mathrm{R}^{2}$ & $\mathrm{~K}$ & $1 / \mathrm{n}$ & $\mathrm{R}^{2}$ \\
\hline \multicolumn{2}{l}{ Unmodified Cocoa Husk Char } & & & & \\
\hline $\mathrm{Cr}$ & 0.409 & 222.22 & 0.8013 & 95.74 & 0.2819 & 0.7817 \\
$\mathrm{~Pb}$ & -1.023 & 227.273 & 0.0088 & 4193.7 & -0.3423 & 0.0656 \\
\hline \multicolumn{2}{l}{ Modified Cocoa Husk Char } & & & & & \\
\hline $\mathrm{Cr}$ & -20.83 & -833.33 & 0.937 & 36.88 & 1.2186 & 0.9687 \\
$\mathrm{~Pb}$ & -0.8428 & 1694.92 & 0.5749 & 3.348 & -2.9356 & 0.6331 \\
\hline
\end{tabular}

$\mathrm{R}^{2}=$ correlation coefficient

\section{Conclusion}

This study showed that the use of agricultural wastes such as maize cob which constitute a nuisance to the environment could be turned to wealth by being processed to serve as cheaper, alternative adsorbents to the commercially available activated carbon for treating heavy metal contaminated wastewater. The removal efficiency was controlled by adsorbent dosage and agitation times, initial ion concentration and particle size. 
Chitosan Grafted Modified Maize Cob For Removal of Lead and Chromium..................KOYA et al.

Langmuir and Freundlich models displayed a better fitting for the $\mathrm{Cr}$ adsorption than $\mathrm{Pb}$ but adsorption data fitted well with the two models. The natural adsorbents exhibit high selectivity for metal ion such as $\mathrm{Pb}^{2+}$ than $\mathrm{Cr}^{6+}$. Using maize cob char to produce activated carbons potentially provide a less expensive raw material, a highly effective adsorbent as well as producing activated carbon processed from renewable resources instead of non-renewable ones. Research should be done on how to modify the agricultural waste for better improvement on treatment of wastewater.

\section{References}

Abdou, E.S., Nagy, K.S.A. and Elsabee, M.Z. (2008) Extraction and characterization of chitin and chitosan from local sources. Bioresource Technology, 99(5): 1359-1367.

AjayKumar, A.V., Darwish, N.A. and Hilal, N. (2009). Study of Various Parameters in the Biosorption of Heavy Metals on Activated Sludge. World Applied Sciences Journal, 5 (Special Issue for Environment): 3240.

Alayande, O., Akinlabi, A., Olalekan, D. and Okesola, B. (2011). Valuable potentials of cowpea husk waste. International Journal of Chemical Science, 4(2): 358-361.

Alfa, Y.M., Hassan, H. and Nda-Umar, U.I. (2012). Agricultural Waste Materials as Potential Adsorbent for Removal of Heavy Metals from Aqueous Solutions. International Journal of Chemical Research, 2(2): 01-13.

Al-Sultani, K.F. and Al-Seroury, F.A. (2012). Characterization the Removal of Phenol from Aqueous Solution in Fluidized Bed Column by Rice Husk
Adsorbent. Research Journal of Recent Science. 1: 145-151.

Amuda O.S., Adelowo, F.E. and Ologunde, M.O. (2009). Kinetics and equilibrium studies of adsorption of chromium(VI) ion from industrial wastewater using Chrysophyllum albidum (Sapotaceae) seed shells Coll. Surf B: Biointerfaces, 68:184192.

Amuda, O.S., Giwa, A.A. and Bello, I.A. (2007). Removal of heavy metal from industrial wastewater using modified activated coconut shell carbon. Biochechemical Engineering Journal. 36: 174-181.

Amuda, O.S. and Ibrahim, A.O. (2006). Industrial wastewater treatment for chemical oxygen demand (COD) using natural material as adsorbent, African J. Biotechnol., 5(16): 14831487

Edwin, V.A. (2008). Surface Modification of Activated Carbon for enhancement of Nickel (II) adsorption. Electronic J. Chem., 5(4): 814-819.

Gönen, F. and Serin, D.S. (2012). Adsorption study on orange peel: Removal of $\mathrm{Ni}$ (II) ions from aqueous solution. African Journal of Biotechnology, 11(5): 1250-1258.

Grabriela, H.P., Luciana, M.S., Mauricio, L. T., Gustavo, A., and Saavedra, P. (2006). "Biosorption of Cadmium by green coconut shell powder" Science Direct Mineral Engineering, 19: 380387.

Ijagbemi, C.O., and Dong-Su, K. (2009). Sorbent Characteristics of Montmorillonite for $\mathrm{Ni}^{2+}$ Removal from Aqueous Solution. Environ. Eng. Res. 14(1): 26-31

Kadirvelu, K., Thamaraiselvi, C. and Namasivayam, C. (2001). Adsorption of nickel (II) from aqueous solution onto activated carbon prepared from 
coirpith. Separation and Purification Technology, 24: 497-505.

Kartal, S.N., Kose, C., Tarakanadha, B. and Imamura, Y. (2008) Adsorption of copper, chromium and arsenic from chromated copper arsenate (CCA) treated wood unto various adsorbents. Open Waste Manage. J., 1: $11-17$

Kocaoba, S., Orhan, Y. and Akyüz, T. (2007). Kinetics and equilibrium studies of heavy metal ions removal by use of natural zeolite. Desalination, 214: 1-10.

Kose, T. D., Gharde, B. D. and Gholse, S. B. (2012) Studies on albizia procera legumes for effective removal of $\mathrm{Fe}$ (II) and $\mathrm{Mn}$ (II) from aqueous solution. J. Chem. Pharm. Res., 4(4): 2021-2028.

Leusch, A. and Volesky, B. (1995) The influence of film diffusion on cadmium biosorption by marine biomass. Journal of Biotechnology., $43 ; 1-10$.

Mahmoud, N.S., Atwa, S.T., Sakr, A.K. and Abdel Geleel, M. (2012). Kinetic and Thermodynamic Study of the Adsorption of Ni (II) using Spent Activated Clay Mineral. New York Science Journal, 5(2): 62-68.

Michaud C.F. (2011). "Ion Exchange Reaction - A Review" Water conditioning and Purification. Spotlight Article. http://www.wcponline.com/pdf/1104 Michaud.pdf_ Accessed 26 June 2013

Nesernejad, B., Zadeh, T.E. and Zamani, A. (2004). comparison for biosorption modelling of heavy metals (Cr III, $\mathrm{Cu}$ II, $\mathrm{Zn}$ II) adsorption from wastewater by carrot residues. Process Biochem., 40: 1319 $-1322$
Nriagu, J. (1996). A history of global metal pollution. Int. J. Eng. Res. App., pp. $1-223$.

Okoya, A.A., Akinyele A.B., Ofoezie, I. E., Amuda O.S., Alayande, O. S. and Makinde O.W. (2014). Adsorption of heavy metal ions onto chitosan grafted cocoa husk char. African Journal of Pure and Applied Chemistry 8(10): 147-161.

Oliveira, F.D., Soares, A.C., Freitas, O.M. and Figueiredo, S.A. (2010). Copper, Nickel and Zinc Removal by Peanut Hulls: Batch and Column Studies in Mono, Tri-Component Systems and with Real Effluent. Global Nest Journal, 12(2): 206 - 214.

Olu-owolabi, B.I., Oputu, O.U., Adebowale, K.O., Ogunsolu, O. and Olujimi, O.O. (2012). Biosorption of $\mathrm{Cd}^{2+}$ and $\mathrm{Pb}^{2+}$ ions onto mango stone and cocoa pod waste: Kinetic and equilibrium studies. Scientific Research and Essays, 7(15): 1614-1629.

Onundi, Y.B., Mamun, A.A., Al Khatib, M.F., Al Saadi, M.A. and Suleyman, A.M. (2011). Heavy metals removal from synthetic wastewater by a novel nano-size composite adsorbent. International Journal of Environmental Science and Technology, 8(4): 799-806.

Sprynskyy, M., Buszewski B., Terzyk A.P. and Namiesnik J. (2006). Study of the selection mechanism of heavy metal $\left(\mathrm{Pb}^{2+}, \mathrm{Cu}^{2+}, \mathrm{Ni}^{2+}\right.$ and $\left.\mathrm{Cd}^{2+}\right)$ adsorption on clinoptilolite, Journal of Colloid and Interface Science, 304, 21-28.

Subramani, T. and Sindhu, S. (2012). Batch Study Experiments and Column Analysis for finding out a Suitable Biosorbent for the Removal of Heavy Metals from Electroplating 
Chitosan Grafted Modified Maize Cob For Removal of Lead and Chromium.................KOYA et al.

Industry Effluent. Int. J. Eng. Res. App., 2(4): $172-184$.

Sud, D., Mahajan, G and Kaur, N.P. (2008). Agricultural waste material as potential adsorbent for sequestering heavy metal ions form aqueous solutions - A review, Bioresour. Technol., 99: 6017-6027.

Sugashini, S. and Gopalakrishnan, S. (2012). Studies on the Performance of Protonated cross linked Chitosan Beads (PCCB) for Chromium Removal. Research Journal of Chemical Sciences, 2(6): 55-59.
WHO (1972). Health Hazard to Human Environment, World Health Organisation, 1972.

Zhen, Y., Hu, Y., Ziwen, J., Tao C., Haijiang L., Haibo, L., Aimin, L. and Rongshi, C. (2013). Flocculation of both anionic and cationic dyes in aqueous solutions by the amphoteric grafting flocculant carboxymethyl chitosan-graft-polyacrylamide.

Journal of Hazardous Materials, 254-255: 36-45. 